\title{
Glutamate receptor GluAl subunit is implicated in capsaicin induced modulation of amygdala LTP but not LTD
}

\author{
Christine Gebhardt and Doris Albrecht \\ Institute of Neurophysiology, Charité - Universitätsmedizin Berlin, CCM, CCO, 10117 Berlin, Germany
}

\begin{abstract}
Capsaicin has been shown to modulate synaptic plasticity in various brain regions including the amygdala. Whereas in the lateral amygdala the modulatory effect of capsaicin on long-term potentiation (LA-LTP) is mediated by TRPV1 channels, we have recently shown that capsaicin-induced enhancement of long term depression (LA-LTD) is mediated by TRPMI receptors. However, the underlying mechanism by which capsaicin modulates synaptic plasticity is poorly understood. In the present study, we investigate the modulatory effect of capsaicin on synaptic plasticity in mice lacking the AMPAR subunit GluA1. Capsaicin reduced the magnitude of LA-LTP in slices derived from wild-type mice as previously described, whereas this capsaicin-induced suppression was absent in GluAl-deficient mice. In contrast, neither LA-LTD nor the capsaicin-mediated enhancement of LA-LTD was changed in GluAl knockout mice. Our data indicate that capsaicin-induced modulation of LA-LTP via TRPV1 involves GluAl-containing AMPARs whereas capsaicin-induced modulation of LALTD via TRPMl is independent of the expression of the AMPAR GluAl subunit.
\end{abstract}

The lateral amygdala (LA) receives sensory and cortical information and has been identified as a key structure for fear memory. Fear conditioning and extinction depend on intact long-term increases (LTP) or decreases (long-term depression, LTD) in synaptic efficacy in the LA.

In horizontal slices, LA-LTP and LA-LTD can be elicited by stimulation of external capsule fibers (EC) or intranuclear afferents (intranuclear stimulation, IN) with different induction and expression mechanisms (Drephal et al. 2006; Schubert and Albrecht 2008; Müller et al. 2009). In contrast to coronal slices, stimulation of EC fibers in horizontal slices includes afferents from the lateral entorhinal and perirhinal cortex that also synapse in the LA (von Bohlen und Halbach and Albrecht 2002). Stimulation within the LA also activates local connections within the LA and afferents from other amygdaloid nuclei (von Bohlen und Halbach and Albrecht 2002).

Induction of LA-LTP requires a high increase in intracellular calcium which is, depending on the induction protocols and the stimulated afferents, mainly mediated by NMDA receptors, voltage-gated $\mathrm{Ca}^{2+}$ channels (Bauer et al. 2002; Drephal et al. 2006; Fourcaudot et al. 2009) or group I metabotropic GluRs (Lee et al. 2002). LTD induction requires a moderate increase in intracellular calcium due to activation of postsynaptic NMDARs, group II mGluRs or L-type calcium channels (Kaschel et al. 2004; Tchekalarova and Albrecht 2007; Lucas et al. 2013). Previous studies in horizontal slices of the LA have shown that the application of LFS to presynaptic fibers within the LA reliably elicits LTD (intranuclear; IN) (Tchekalarova and Albrecht 2007; Müller et al. 2009), whereas stimulating fibers in the EC does not (Müller et al. 2009).

Excitatory responses in the LA evoked by electrical stimulation of afferents, are predominantly mediated by AMPA receptors (AMPARs). AMPARs are homo- and hetero-tetramers assembled from the subunits GluA1-GluA4 (Traynelis et al. 2010). In the LA, the majority of AMPARs in projection neurons contain the

\section{Corresponding author: christine.gebhardt@charite.de} Article is online at http://www.learnmem.org/cgi/doi/10.1101//m.045948.117.
GluA2 subunit composed by GLUA1/GluA2 or GluA2/GluA3 hetero-tetramers whereas on interneurons AMPARs lacking GluA2 have been described (Sah and Lopez De Armentia 2003). Insertion or removal of synaptic AMPARs are known to underlie various forms of LTP and LTD in the LA. The GluA1 subunit is critical for the expression of LA-LTP, fear conditioning, anxiety, and aggression (Vekovischeva et al. 2004; Rumpel et al. 2005; Feyder et al. 2007; Humeau et al. 2007; Nedelescu et al. 2010; Tran and Keele 2016).

Members of the transient receptor potential (TRP) channel family, a family of nonselective cation channels, have been shown to modify synaptic plasticity in various brain regions including the hippocampus (Gibson et al. 2008; Li et al. 2008; Chávez et al. 2010; Menigoz et al. 2016), entorhinal cortex (Banke 2016), nucleus accumbens (Grueter et al. 2010), and superior colliculus (Maione et al. 2009). In the LA, we have previously demonstrated that LTP is attenuated by capsaicin via activation of TRPV1 (Zschenderlein et al. 2011) whereas LTD is enhanced by capsaicin via activation of TRPM1 (Gebhardt et al. 2016).

In the present study, we investigate the effect of capsaicin on LA-LTP and LA-LTD in horizontal brain slices from genetically modified mice lacking AMPAR subunit GluA1. Here, we find a significant attenuation of high frequency stimulation (HFS)-induced LTP in slices from homozygous (-/-) and heterozygous (+/-) mice by stimulation of EC or IN fibers as well as an absence of the capsaicin-induced alteration of LA-LTP which was observed in wild-type (wt) mice. In contrast, LA-LTD induced by low frequency stimulation (LFS) was unaltered in slices from homozygous (-/-) and heterozygous (+/-) mice and the capsaicin-induced effect on LA-LTD was preserved.

(C) 2018 Gebhardt and Albrecht This article is distributed exclusively by Cold Spring Harbor Laboratory Press for the first 12 months after the full-issue publication date (see http://learnmem.cshlp.org/site/misc/terms.xhtml). After 12 months, it is available under a Creative Commons License (AttributionNonCommercial 4.0 International), as described at http://creativecommons. org/licenses/by-nc/4.0/. 


\section{Results}

\section{LA-LTP is significantly reduced in homozygous and heterozygous GluAl knockout mice}

GluA1-dependent mechanisms of glutamatergic synaptic plasticity have been shown to be pathway specific in coronal slices. Here, we study LA-LTP in horizontal slices, because LA projection neurons receive different afferent inputs than those in coronal slices: whereas in coronal slices the cortico- and the thalamic LA pathway can be used for stimulation, in horizontal slices LA-LTP also can be induced by stimulation of intranuclear fibers within the LA (IN-LA). We initially tested the I/O curves in slices derived from male and female homozygous $\mathrm{GluA1}^{-/-}$, heterozygous GluA1 ${ }^{+--}$, and wt GluA1 ${ }^{+/+}$mice to examine the effect of GluA1 on synaptic function in the amygdala using the IN-LA stimulation site. No significant differences in I/ $\mathrm{O}$-curves between the groups or sexes were observed (Fig. 1A,B), which shows that basal transmission was not impaired in the examined LA-afferents in GluA1 mutant mice. Next, we examined whether HFS could induce a stable LA-LTP in horizontal slices of homozygous, heterozygous GluA1 mice and wt GluA1 ${ }^{+/+}$ mice. Consistent with earlier findings from horizontal slices derived from rats or mice (Drephal et al. 2006; Müller et al. 2009), our HFS protocol applied to afferents fibers running within the LA (IN-LA) and to afferents running through the external capsule (EC-LA) induced a significant increase in field potential amplitude in male wt GluA $1^{+/+}$mice (IN-LA: $146.4 \pm 4.5 \%$ [ $n=9$ slices], Fig. 1C; EC-LA: $146.4 \pm 3.8 \%$ [ $n=11$ slices], Fig. 2A). However, the magnitude of both IN-LA LTP $\left(\mathrm{GluA1}^{+/-}: 124.8 \pm 4.0 \%\right.$ [ $n=8$ slices], Fig. 1E; GluA1 ${ }^{-/-}: 124.1 \pm$ $5.8 \%$ [ $n=8$ slices], Fig. 1G) and EC-LA LTP $\quad\left(\mathrm{GluA1}^{+/-}\right.$: $\quad 129.8 \pm 6.6 \% \quad[n=11$ slices], Fig. 2B; GluA1 ${ }^{-1-}$ : $120.6 \pm 3.9 \%$ [ $n=10$ slices], Fig. 2C) was significantly reduced in male heterozygous and male homozygous GluA1 deficient mice compared with LTP magnitude in wt $\mathrm{GluA}^{+/+}$mice as illustrated in the bar graph (Figs. 1I, 2D).

The HFS-induced potentiation of the field potential amplitudes (IN-LA) was also observed in female wt $\mathrm{GluA}^{+/+}$ mice $(150.7 \pm 7.2 \% \quad[n=8$ slices $]$; Fig. $1 D)$, female GluA1 ${ }^{+/-}$mice $(117.9 \pm 6.0 \%$ $[n=12$ slices], Fig. 1F) and female GluA1 $^{-/-}$mice $(127.3 \pm 6.5 \%[n=8$ slices]; Fig. 1H). We did not find any significant difference in IN-LA LTP between males and females.

\section{IN-LA [ether]}

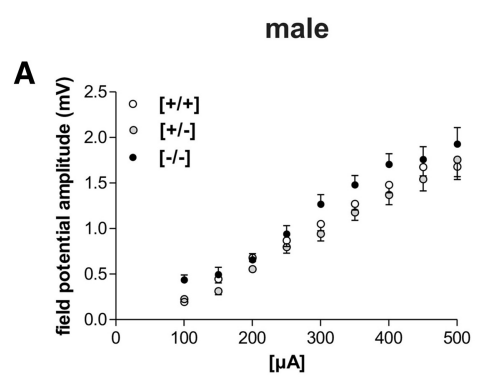

B
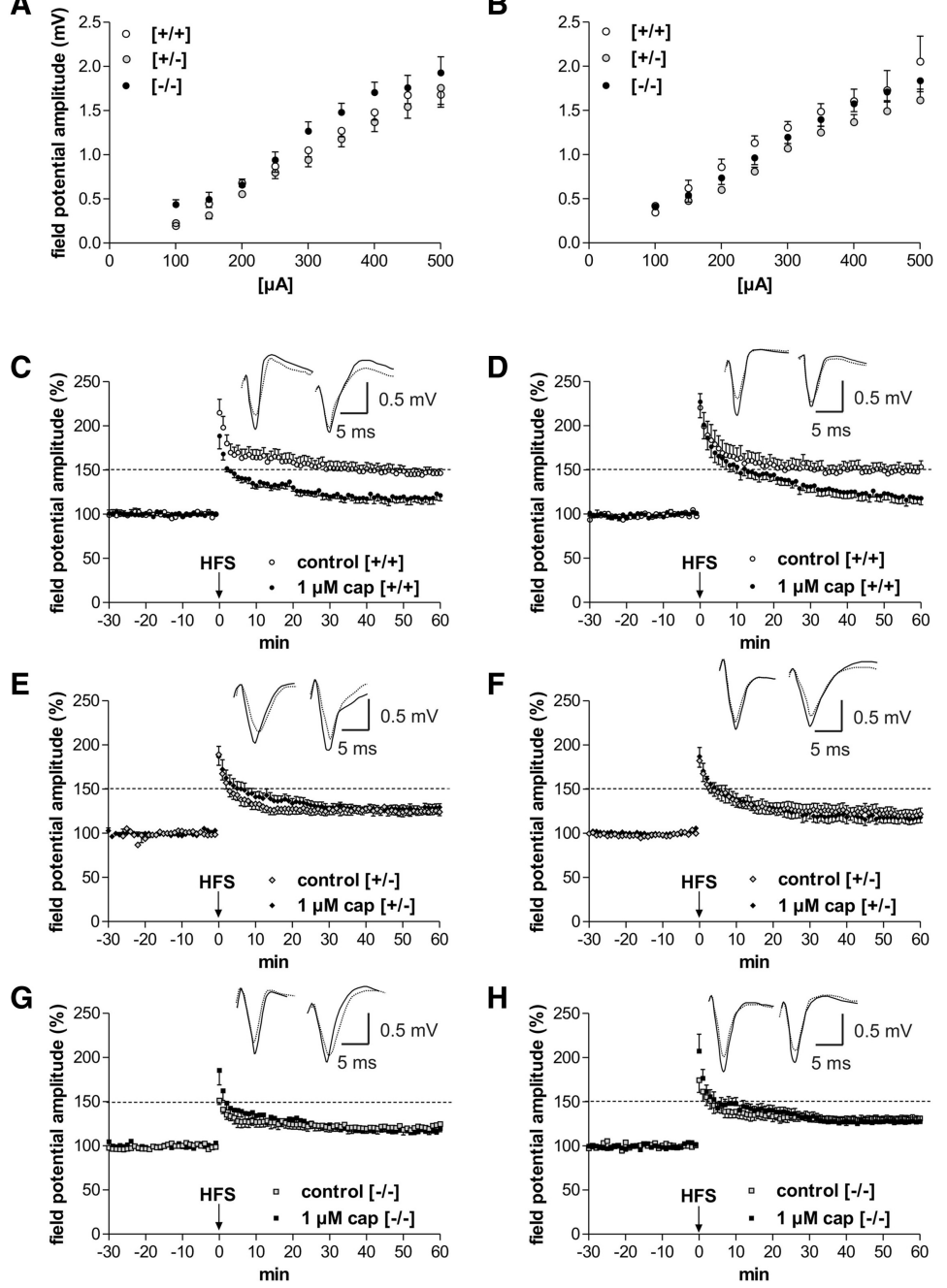

H
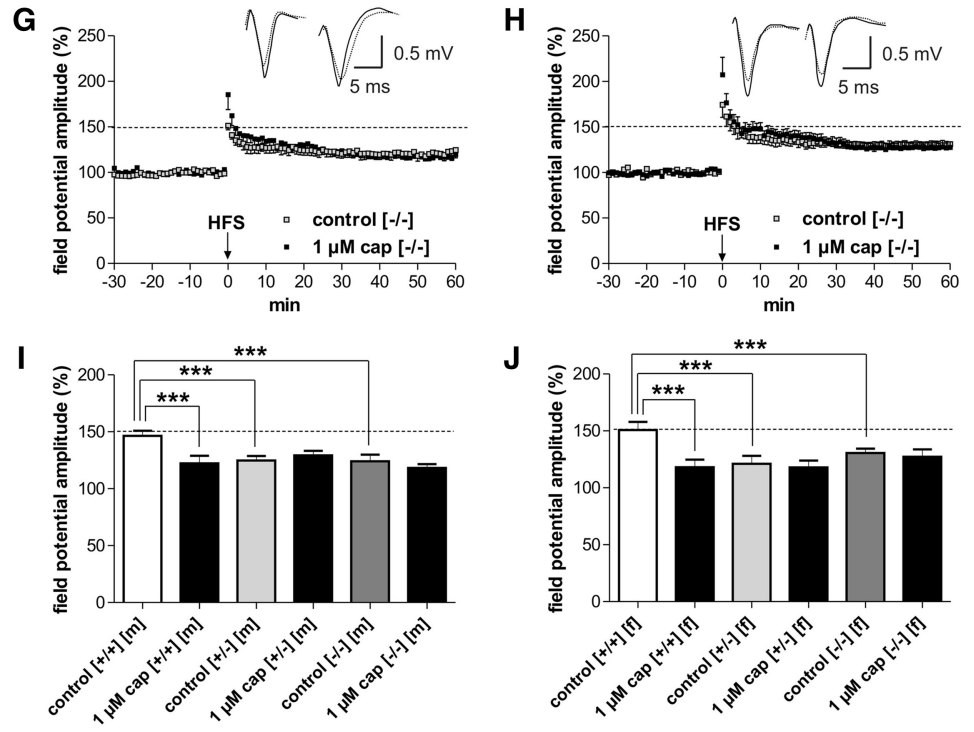

Figure 1. Capsaicin-mediated reduction of LA-LTP induced by intranuclear stimulation (IN) in slices derived from male and female wt mice is absent in GluA1 knockout mice. (A) Input/output curves recorded in horizontal brain slices derived from male wild-type (wt) mice $\left(n=39\right.$ slices), GluA $1^{+/-}(n=28$ slices), and GluA1 ${ }^{-1-}$ knockout mice $(n=41$ slices). (B) Input/output curves recorded in horizontal brain slices derived from female wt mice $\left(n=35\right.$ slices), GluA $1^{+-}$( $n=40$ slices), and GluA $1^{-1-}$ knockout mice ( $n=39$ slices). Basal transmission was not significantly different in mutant mice compared with wt. Capsaicin significantly reduced LA-LTP after HFS of fibers running through the LA in male $(m)(C)$ and female $(f)(D)$ wt mice. $(E, F)$ The capsaicin-induced suppression of LA-LTP is missing in heterozygous GluA1 knockout mice. $(G, H)$ The capsaicin-induced suppression of LA-LTP is also missing in homozygous GluA1 knockout mice. Data points represent averaged amplitudes (mean \pm SEM) normalized with respect to baseline values. Representative traces were recorded 5 min prior to tetanus (dashed lines) and 60 min after tetanic stimulation (solid lines) in the LA. $(I, J)$ Bar histograms of data points averaged 59 to $60 \mathrm{~min}$ after HFS, and normalized with respect to baseline (mean \pm SEM). Significant differences are indicated. $\left.{ }^{* * *}\right) P<0.001$. 


\section{EC-LA [male, ether]}
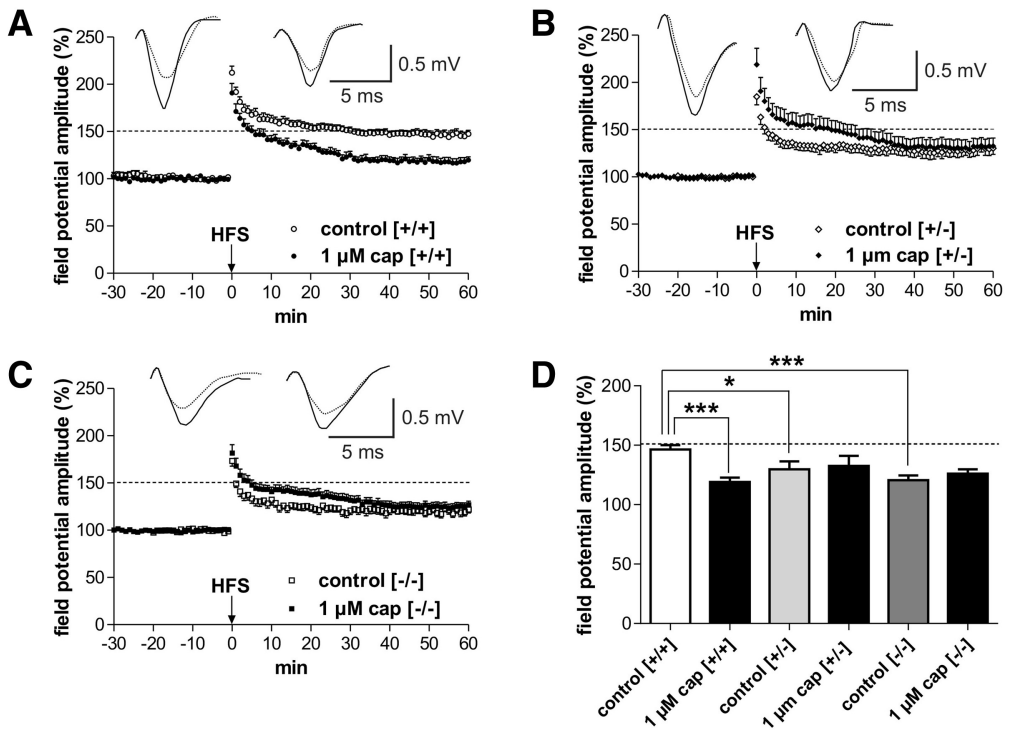

Figure 2. Capsaicin-induced reduction of EC-induced LA-LTP in slices derived from wt mice is absent in GluA1 knockout mice. $(A)$ Capsaicin significantly reduced LA-LTP after high-frequency stimulation (HFS) of external capsule fibers (EC) in male wt mice in comparison with controls. $(B, C)$ The capsaicin-induced suppression of LA-LTP is missing in GluA $1^{+/-}$and $\mathrm{GluA} 1^{-/-}$mice. Data points represent averaged amplitudes (mean \pm SEM) normalized with respect to baseline values. Representative traces were recorded $5 \mathrm{~min}$ prior to tetanus (dashed lines) and $60 \mathrm{~min}$ after tetanic stimulation (solid lines) in the LA. (D) Bar histograms of data points averaged 59-60 min after HFS, and normalized with respect to baseline (mean \pm SEM). Significant differences are indicated. $\left(^{*}\right) P<0.05 ;\left({ }^{* *}\right) P<0.001$.

\section{There is no capsaicin-dependent modulation of LA-LTP in homozygous and heterozygous GluAl knockout mice} Our previous data have demonstrated that capsaicin modulates the magnitude of LA-LTP induced by HFS of both EC-fibers and IN-afferents in horizontal slices of $\mathrm{C} 57 \mathrm{Bl} / 6$ mice. This capsaicinmediated modulation depends on the isoflurane concentration during anesthesia. We have observed a similar HFS-induced increase in the magnitude of LA-LTP in mice anesthetized with ether or $4 \%$ isoflurane before decapitation whereas after anesthesia with high isoflurane concentrations (8\%) the magnitude of LA-LTP was significantly smaller (Kulisch et al. 2011). When ether or low isoflurane (4\%) concentration were used for anesthesia capsaicin reduced the magnitude of LA-LTP. In contrast, high isoflurane concentrations (8\%) cause a sensitization of TRPV1 receptor and its activation by capsaicin led to an enhancement of LA-LTP (Zschenderlein et al. 2011). Please note that all experiments were performed using ether anesthesia if not otherwise stated.

As expected, the magnitude of LA-LTP was significantly reduced by $1 \mu \mathrm{M}$ capsaicin in wt littermates (IN-LA: $122.2 \pm 6.7 \%$ [ $n=7$ slices]; $P<0.05$; Fig. 1C; EC-LA: $119.0 \pm 3.7 \%$ [ $n=10$ slices]; $P<0.05$; Fig. 2A). In contrast, in homozygous and heterozygous GluA1 knockout mice, capsaicin did not show a significant effect on IN-LA LTP (GluA1 ${ }^{+/-}$males: $129.2 \pm 4.0 \%$ [ $n=9$ slices]; female $117.9 \pm 6.0 \%$ [ $n=12$ slices]; GluA1 ${ }^{-/-}$males: $118.2 \pm 3.4 \%[n=10$ slices]; females: $127.3 \pm 6.5 \%$ [ $n=8$ slices]; Fig. 1 ). These results indicate that GluA1 is involved in the mediation of capsaicininduced effects on synaptic plasticity in the amygdala in both males and females.

Similarly, in slices of homozygous and heterozygous GluA1 knockout mice capsaicin had no significant effect on EC-LA LTP (GluA1 $^{+/-}$control: $129.8 \pm 6.6 \%$ [ $n=11$ slices] versus cap: $132.6 \pm$ 8.4\% [ $n=15$ slices]; GluA1 ${ }^{-/-}$control: $120.6 \pm 3.9 \%$ [ $n=10$ slices $]$ versus cap: $126.1 \pm 3.7 \%[n=17$ slices $]$ ). Thus, we could not find differences in the involvement of GluA1 subunit in the mediation of TRPV1 activation depending on the input being stimulated.

After high isoflurane anesthesia EC-LA LTP was facilitated by pretreatment with capsaicin in male wild-type mice (drug-free control: $127.6 \pm 3.6 \%[n$ $=9$ slices $]$ versus cap: $154.0 \pm 7.3 \%[n=9$ slices]; $P<0.05$; Fig. 3A,C). The capsaicin-induced enhancement of LA-LTP in the high-isoflurane group could be blocked by the TRPV1 antagonist AMG $9810(130.1 \pm 5.3 \%$ [ $n=9$ slices]; Fig. $3 \mathrm{~A})$ and was not observed in brain slices derived from male GluA1 ${ }^{-/-}$mice (drug-free control: $120.5 \pm 7.3 \%$ [ $n=8$ slices]; Fig. 3B,C). The pretreatment of slices with AMG 9810 and capsaicin did not cause a significant change in the magnitude of LA-LTP in GluA1 knockout mice (AMG 9819 + cap: $116.8 \pm 7.5 \%[n=9$ slices $]$ ). These results, which are summarized in Figure 3C, also support the suggestion that the GluA1 subunit is involved in the mediation of capsaicin-induced effects on LA-LTP.

\section{Genetic deletion of GluAl had no effect on LTD or capsaicin-induced modulation of LTD}

We have recently shown that the application of low-frequency stimulation (LFS, 900 pulses at $1 \mathrm{~Hz}$ ) elicits a strong LTD when stimulating presynaptic fibers within the LA (intranuclear; IN) and that capsaicin significantly enhanced this form of LFS-induced LTD via activation of TRPM1 receptors. Here, we examined whether this LFS-induced IN-LA-LTD is impaired in GluA1 knockout mice. As shown in Figure 4, we did not find any significant differences in IN-LA-LTD between the wt-littermates, heterozygous and homozygous mice or between sexes. In all animal groups, capsaicin caused a significant enhancement of LA-LTD (male +/+: 82.2 $\pm 5.1 \%$ [ $n=9$ slices $]$ versus cap: $69.6 \pm 3.7 \%$ [ $n=10$ slices], $P=0.007$, Fig. $4 \mathrm{~A} ;+/-: 87.2 \pm 4.9 \%[n$ $=8$ slices] versus cap: $75.5 \pm 4.3 \%$ [ $n=9$ slices], $P=0.02$, Fig. $4 \mathrm{C}$; $-/-: 84.5 \pm 5.0 \%$ [ $n=7$ slices] versus cap: $73.5 \pm 5.1 \%$ [ $n=8$ slices], $P=0.04$, Fig. $4 \mathrm{E}$; females $+/+: 86.7 \pm 3.2 \%[n=8$ slices $]$ versus cap: $74.3 \pm 6.7 \%$ [ $n=7$ slices], $P<0.0001$, Fig. $4 \mathrm{~B} ;+/-: 85.6 \pm 3.7 \%[n$ $=10$ slices $]$ versus cap: $72.6 \pm 1.7 \%$ [ $n=7$ slices], $P=0.0007$, Fig. $4 \mathrm{D} ;-/-: 89.6 \pm 7.7 \%[n=7$ slices] versus cap: $72.2 \pm 2.2 \%[n=9$ slices], $P=0.002$, Fig. 4 F). Our results suggest that, in contrast to LA-LTP, LA-LTD and capsaicin-induced effects on LA-LTD are independent of GluA1-containing AMPARs.

\section{Discussion}

The present study shows that LA-LTP was impaired in horizontal brain slices of homo- and heterozygous GluA1 knockout mice. This impairment was independent of stimulation site and activation of TRPV1 receptor did not modulate LA-LTP in these slices.

Furthermore, we did not observe significant gender differences in the magnitude of LA-LTP which is in line with previous data from rat (Drephal et al. 2006) or mice slices (Staschewski et al. 2011) using high frequency stimulation as LTP induction protocol. 


\section{EC-LA [male, high Isoflurane]}

A

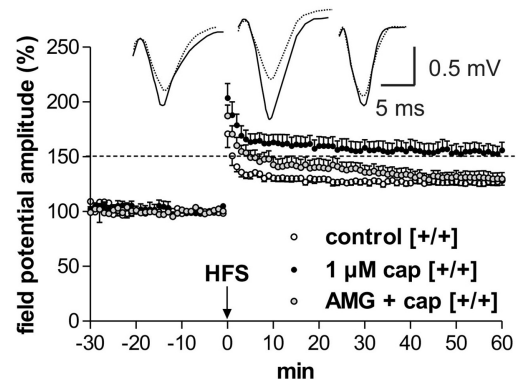

B

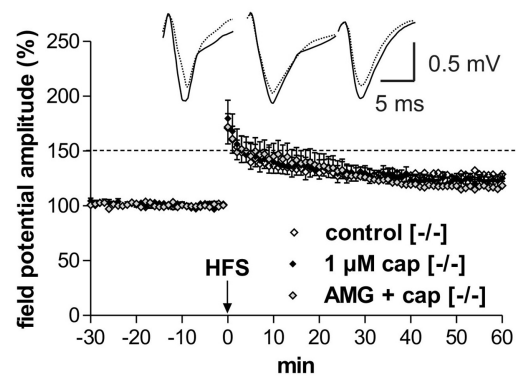

C

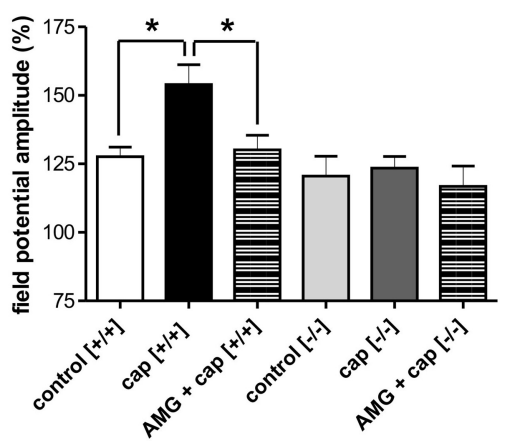

Figure 3. In slices derived from male mice anesthetized with $8 \%$ isoflurane before decapitation LTP-enhancing effect of capsaicin after EC stimulation was absent in GluA1 knockout mice. $(A)$ Deep isoflurane anesthesia before decapitation caused a reduction of LA-LTP in slices derived from male wt mice. In these slices capsaicin evoked a strong increase in the magnitude of LA-LTP. The capsaicin-induced enhancement of LA-LTP could be blocked by the specific TRPV1 antagonist AMG9810. (B) In male GluA1 knockout mice the capsaicin-induced effect on LA-LTP was absent. The co-application of the TRPV1 antagonist together with capsaicin did not change the magnitude of LA-LTP. Data points represent averaged amplitudes (mean \pm SEM) normalized with respect to baseline values. (C) Bar histograms of data points averaged 57 to $60 \mathrm{~min}$ after HFS, and normalized with respect to baseline (mean \pm SEM). Significant differences are indicated. $\left(^{*}\right) P<0.05$.

It is known that hippocampal synaptic structure and function exhibit marked variations during the estrus cycle of female rats (Warren et al. 1995; Prange-Kiel et al. 2009; Sabaliauskas et al. 2015). We have shown that rat amygdala slices prepared from females in proestrus or estrus exhibited greater LA-LTP than slices from females in diestrus (Schubert et al. 2008). The results of our present investigation suggest that LA-LTP obtained during different states of the estrus cycle in female mice are responsible for the missing gender difference.

Conversely, we found that LA-LTD and the modulatory effect of capsaicin on LA-LTD were unchanged in GluA1 knockout mice. Our data also indicate that basal synaptic transmission was intact in GluA1-deficient mice because we did not find significant differ- ences in I/O curves in slices derived from GluA1-deficient and wild-type mice. Presumably, removal of GluA1 containing AMPA receptors mainly affects extrasynaptic receptors in LA neurons whereas remaining and compensatory GluA2/GluA3-containing receptors are transported and targeted to synapses, potentially acting primarily to maintain basal transmission as suggested previously by for hippocampal neurons (Zamanillo et al. 1999).

Impairment of LTP in GluA1 deficient mice was previously reported for CA3 to CA1 synapses (Zamanillo et al. 1999) as well as for thalamic and cortical inputs to LA in coronal slices (Humeau et al. 2007), whereas LTP was unaltered in cortical pyramidal neurons of adult mice (Frey et al. 2009). In our experiments performed in mature adult mice slices LA-LTP was reduced but still inducible in heterozygous and homozygous GluA1-deficient mice using both IN- and EC-stimulation. Recently it has been reported that a strong induction protocol is able to induce LTP in CA1 neurons independent of AMPAR subunit type as long as a sufficient number of extrasynaptic surface-expressed receptors can be recruited to the postsynaptic membrane (Granger et al. 2013). Thus, in GluA1 knockout mice the decreased number of extrasynaptic surfaceexpressed AMPA receptors might account for the LTP impairment in CA1 neurons. However, it is unclear whether trafficking and surface expression of synaptic AMPA receptors in LA neurons are similarly regulated as in hippocampal synapses. For instance, it has been recently hypothesized that synaptic recruitment of AMPA receptors from extracellular sites is regulated differently in hippocampal and visual cortical synapses, which indicates that synaptic AMPA receptor regulation might depend on brain region specific mechanisms (He et al. 2011).

Here, we show for the first time that the modulatory effect of capsaicin on the magnitude of LA-LTP is dependent on AMPAR. In a previous study, we found that capsaicin-induced attenuation of LA-LTP is absent in nNOS ${ }^{-/}$mice and that it can be blocked by application of the unspecific NOS antagonist L-Name (Zschenderlein et al. 2011). However, NOS inhibitors and genetic deletion of neuronal NOS decrease binding of GluA1 to stargazin, a member of the family of transmembrane AMPAR regulatory proteins (TARPs), which mediates surface expression of AMPARs (Selvakumar et al. 2009). Our data indicate that the capsaicin-induced changes in LA-LTP are selective for GluA1-containing AMPARs, suggesting that capsaicin might inhibit surface expression of GluA1 containing AMPARs via the NOS pathway.

Sensitization of TRPV1 by a high dosage of isoflurane before decapitation of mice causes capsaicin to increase LA-LTP instead of decreasing it (Zschenderlein et al. 2011). This increase of LA-LTP could be blocked by a specific TRPV1 receptor antagonist and was not present in GluA1 knockout mice. A similar effect of capsaicin on regulation of synaptic AMPARs was observed in nonpeptidergic C-fibers. In a capsaicin model of acute inflammatory hyperalgesia, synapses exhibited potentiation due to a significantly higher density of GluA1 containing AMPARs after capsaicin application (Larsson and Broman 2008). In accordance with these observations, GluA1 knockout mice show reduced acute inflammatory hyperalgesia (Hartmann et al. 2004).

In contrast to our results obtained in LTP experiments, LA-LTD induced by LFS of fibers running through the LA deriving not only from the cortical areas but also from the basolateral nucleus of the amygdala was unaffected in GluA1 deficient mice. As for LTP the role of AMPARs in LTD is best investigated in hippocampal neurons. Although previous studies suggested that dephosphorylation of GluA1 subunit may have a role in hippocampal LTD (Lee et al. 2003, 2010), LTD was still inducible in CA1 pyramidal neurons where GluA1 subunit was constitutively knocked out (Granger and Nicoll 2014) as well as in hippocampal slices with genetic deletion of GluA1 (Selcher et al. 2012). 


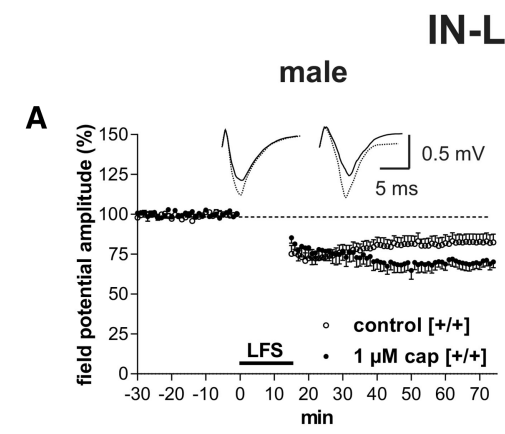

C

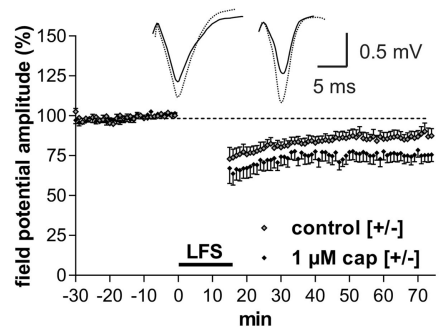

E

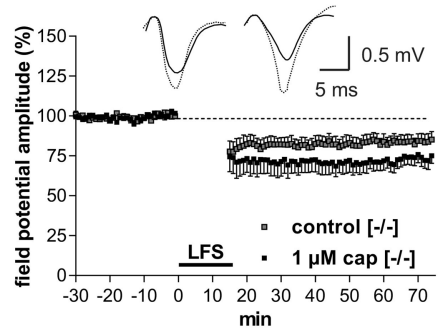

G

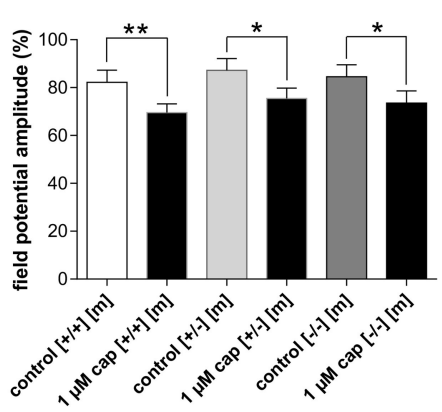

female

B

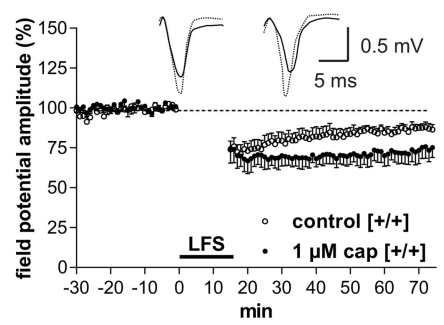

D

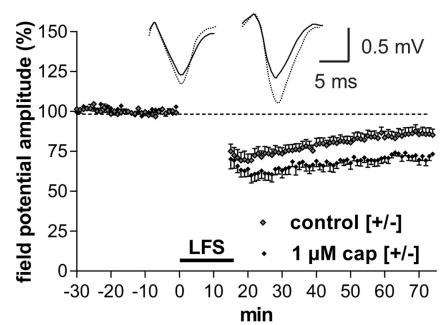

$\mathbf{F}$

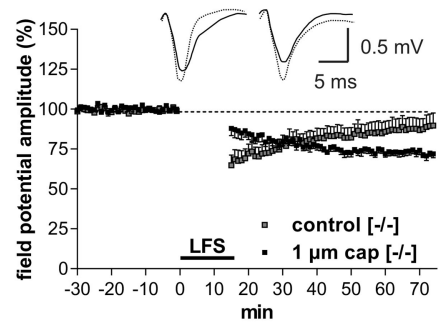

H

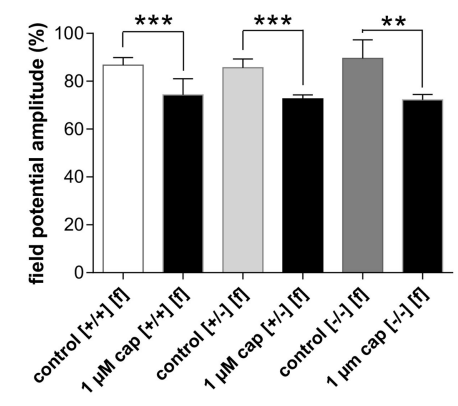

Figure 4. Capsaicin-induced enhancement of LA-LTD induced by intranuclear stimulation (IN) in slices derived from male and female wt mice is preserved in GluA1 knockout mice. Capsaicin significantly enhanced LA-LTD after LFS of fibers running through the LA in male $(\mathrm{m})(A)$ and female $(\mathrm{f})(B)$ wt mice. $(C$, $D)$ The capsaicin-induced enhancement of LA-LTD is preserved in heterozygous GluA1 knockout mice. $(E, F)$ The capsaicin-induced enhancement of LA-LTD is also preserved in homozygous GluA1 knockout mice. Data points represent averaged amplitudes (mean \pm SEM) normalized with respect to baseline values. Representative traces were recorded $5 \mathrm{~min}$ prior to tetanus (dashed lines) and $60 \mathrm{~min}$ after tetanic stimulation (solid lines) in the LA. $(G, H)$ Bar histograms of data points averaged 59 to 60 min after LFS, and normalized with respect to baseline (mean \pm SEM). Significant differences are indicated. $\left(^{*}\right) P<0.05 ;(* *) P<0.01 ;\left({ }^{* *}\right) P<0.001$.

In a previous study, we have identified several physiological mechanisms, which contribute to the capsaicin-induced enhancement of LA-LTD (i.e., antagonists of Group I mGluR, NMDAR, and TRPC channels block capsaicin-induced LA-LTD). Furthermore, we showed an involvement of GABAergic interneurons (Gebhardt et al. 2016). Our finding that neither LA-LTD nor the capsaicin-induced enhancement of LA-LTD depend on GluA1 AMPAR subunit in LA neurons supports the hypothesis that reduction in synaptic strength is independent of glutamate receptor subtype in the LA.

\section{Materials and Methods}

\section{Animals and housing}

The gene-targeted mouse lines for the GluA1 knockout were generated in the laboratory of R. Sprengel and have been described in detail (Zamanillo et al. 1999). The GluA1 knockout mice are kept as a heterozygous line. For electrophysiological experiments, the colonies of wild-type and knockout mice were simultaneously produced by pairing heterozygous mice from this line. We monitored breeding continuously by assessing the genetic status of the animals by performing PCR on the tail-tip of each mouse. At the time of the extracellular electrophysiological recordings, wt and GluA1 knockout mice were 3 to 5 mo old. To preclude bias, the experimenters measuring LTP or LTD were blinded to the genotype of the mice analyzed. Animals were housed in standardized conditions with an artificial 12-h darklight cycle, room temperature of $22^{\circ} \mathrm{C}$ and approximately $80 \%$ humidity. Mice had free access to food and water. In the past, the extent of sex-biased effects in mammals was obscured by the fact that most investigators examined animals of only one sex (typically males) or did not specifically mention the sex of the tested animals (Jazin and Cahill 2010). Moreover, it has been shown that an interaction between gonadal steroids and glutamate involves hormone regulation of glutamate receptors (Diano et al. 1997; Palomero-Gallagher et al. 2003). To consider this issue, we performed our electrophysiological experiments partly both in males and females. The estrus cycle was not monitored in intact, cycling mice. All of the experimental protocols were approved by government authorities (Landesamt für Gesundheit und Soziales Berlin ID: T0344/05 and T0381/ 11) and performed according to the German Animal Welfare Act of May 25, 1998, and the European Communities Council Directive of November 24, 1986 (86/609/EEC). All efforts were made to minimize suffering. Between three and eight animals were used for each extracellular experiment ( $n=$ number of slices).

\section{Electrophysiology}

The mice were anesthetized with ether and decapitated (Kulisch et al. 2011). Because isoflurane can cause TRPV1 sensitization (Harrison and Nau 2008), mice were anesthetized with $8 \%$ isoflurane for sensitization (Kulisch et al. 2011) and decapitated in an additional series. The brains were quickly removed and placed in ice-cold artificial cerebrospinal fluid (ACSF) (in mM: $129 \mathrm{NaCl}$, $3 \mathrm{KCl}, 1.6 \mathrm{CaCl}_{2}, 1.8 \mathrm{MgSO}_{4}, 1.25 \mathrm{NaH}_{2} \mathrm{PO}_{4}, 10$ glucose, and $\left.21 \mathrm{NaHCO}_{3}\right)$. For extracellular recordings, hemisected horizontal slices $(400 \mu \mathrm{m})$ were prepared using a vibroslicer (Campden Instruments) and placed in an interface chamber, where they were allowed to equilibrate for $120 \mathrm{~min}$ at $35^{\circ} \mathrm{C}$. The slices were superfused continuously with ACSF $(1.2 \mathrm{~mL} / \mathrm{min})$. The $\mathrm{pH}$ was maintained at $7.4\left(95 \% \mathrm{O}_{2}\right.$ and $\left.5 \% \mathrm{CO}_{2}\right)$. Glass microelectrodes (Science Products) were filled with ACSF (tip resistance $3 \mathrm{M} \Omega$ ) 
and placed in the LA to record field potentials. Bipolar stimulation electrodes were used to stimulate fibers within the LA (IN) or in the external capsule (EC). An input/output response curve was constructed by varying the intensity of the single-pulse stimulation and averaging six responses per intensity. The stimulus intensity that evoked a field potential with amplitude equal to $50 \%$ of the maximal response was then used for all subsequent stimulations. Once a stable baseline of responses had been obtained for at least $20 \mathrm{~min}$, either HFS (two trains at $100 \mathrm{~Hz}, 1 \mathrm{sec}$ duration, $30 \mathrm{sec}$ apart) was delivered as to induce LTP or low frequency stimulation (LFS; $1 \mathrm{~Hz}, 15 \mathrm{~min}$ ) was applied to induce LTD (Müller et al. 2009). Subsequent responses to single stimuli were recorded for at least 60 min, and their amplitude quantified as a percent change with respect to baseline. The HFS paradigm was chosen because theta burst stimulation did not produce consistent and reliable induction of LA-LTP.

\section{Drug application}

All drugs were bath-applied at the indicated concentrations starting at least 30 min before HFS or LFS. Capsaicin and AMG 9810 was obtained from Tocris Bioscience.

\section{Data analysis}

Extracellular data were collected and averaged using the custommade software Signal 2 (Cambridge Electronic Design). We defined the field potential amplitude as the absolute DC voltage of a vertical line running from the minimal point of the field potential to its intersection with a line running tangential to the field potential onset and offset points. The significance of differences between groups ( $n=$ number of slices) was calculated with a two-way ANOVA (GraphPad Prism 5; GraphPad software). Significance was set at $P<0.05$. To express and compare changes in the amplitudes of the field potentials between the animal groups, we averaged responses from the period of 59 to 60 min after HFS or LFS.

\section{Acknowledgments}

We thank R. Sprengel for providing GluA1 mutant mice. We also thank Roland Schneider and Sebastian Haufe for excellent technical and experimental assistance and Stephen Lenzi for critical reading the manuscript. This work was supported by the DFG (Al 342/ 12-1). The funder had no role in study design, data collection, data analysis, decision to publish, or manuscript preparation.

\section{References}

Banke TG. 2016. Inhibition of TRPV1 channels enables long-term potentiation in the entorhinal cortex. Pflugers Arch 468: 717-726.

Bauer EP, Schafe GE, LeDoux JE. 2002. NMDA receptors and L-type voltage-gated calcium channels contribute to long-term potentiation and different components of fear memory formation in the lateral amygdala. J Neurosci 22: 5239-5249.

Chávez AE, Chiu CQ, Castillo PE. 2010. TRPV1 activation by endogenous anandamide triggers postsynaptic long-term depression in dentate gyrus. Nat Neurosci 13: 1511-1518.

Diano S, Naftolin F, Horvath TL. 1997. Gonadal steroids target AMPA glutamate receptor-containing neurons in the rat hypothalamus, septum and amygdala: a morphological and biochemical study. Endocrinology 138: 778-789.

Drephal C, Schubert M, Albrecht D. 2006. Input-specific long-term potentiation in the rat lateral amygdala of horizontal slices. Neurobiol Learn Mem 85: 272-282.

Feyder M, Wiedholz L, Sprengel R, Holmes A. 2007. Impaired associative fear learning in mice with complete loss or haploinsufficiency of AMPA GluR1 receptors. Front Behav Neurosci 1: 4

Fourcaudot E, Gambino F, Casassus G, Poulain B, Humeau Y, Lüthi A. 2009. L-type voltage-dependent $\mathrm{Ca}\left({ }^{2+}\right)$ channels mediate expression of presynaptic LTP in amygdala. Nat Neurosci 12: 1093-1095.

Frey MC, Sprengel R, Nevian T. 2009. Activity pattern-dependent long-term potentiation in neocortex and hippocampus of GluA1 (GluR-A) subunit-deficient mice. J Neurosci 29: 5587-5596.

Gebhardt C, von Bohlen und Halbach O, Hadler MD, Harteneck C, Albrecht D. 2016. A novel form of capsaicin-modified amygdala LTD mediated by TRPM1. Neurobiol Learn Mem 136: 1-12.
Gibson HE, Edwards JG, Page RS, Van Hook MJ, Kauer JA. 2008. TRPV1 channels mediate long-term depression at synapses on hippocampal interneurons. Neuron 57: 746-759.

Granger AJ, Nicoll RA. 2014. LTD expression is independent of glutamate receptor subtype. Front Synaptic Neurosci 6: 15.

Granger AJ, Shi Y, Lu W, Cerpas M, Nicoll RA. 2013. LTP requires a reserve pool of glutamate receptors independent of subunit type. Nature 493: 495-500.

Grueter BA, Brasnjo G, Malenka RC. 2010. Postsynaptic TRPV1 triggers cell type-specific long-term depression in the nucleus accumbens. Nat Neurosci 13: 1519-1525.

Harrison N, Nau C. 2008. Sensitization of nociceptive ion channels by inhaled anesthetics - a pain in the gas? Mol Pharmacol 74: 1180-1182.

Hartmann B, Ahmadi S, Heppenstall PA, Lewin GR, Schott C, Borchardt T, Seeburg PH, Zeilhofer HU, Sprengel R, Kuner R. 2004. The AMPA receptor subunits GluR-A and GluR-B reciprocally modulate spinal synaptic plasticity and inflammatory pain. Neuron 44: 637-650.

He K, Goel A, Ciarkowski CE, Song L, Lee HK. 2011. Brain area specific regulation of synaptic AMPA receptors by phosphorylation. Commun Integr Biol 4: 569-572.

Humeau Y, Reisel D, Johnson AW, Borchardt T, Jensen V, Gebhardt C, Bosch V, Gass P, Bannerman DM, Good MA, et al. 2007. A pathway-specific function for different AMPA receptor subunits in amygdala long-term potentiation and fear conditioning. J Neurosci 27: 10947-10956.

Jazin E, Cahill L. 2010. Sex differences in molecular neuroscience: from fruit flies to humans. Nat Rev Neurosci 11: 9-17.

Kaschel T, Schubert M, Albrecht D. 2004. Long-term depression in horizontal slices of the rat lateral amygdala. Synapse 53: 141-150.

Kulisch C, Eckers N, Albrecht D. 2011. Method of euthanasia affects amygdala plasticity in horizontal brain slices from mice. J Neurosci Methods 201: 340-345.

Larsson M, Broman J. 2008. Translocation of GluR1-containing AMPA receptors to a spinal nociceptive synapse during acute noxious stimulation. J Neurosci 28: 7084-7090.

Lee OK, Lee CJ, Choi S. 2002. Induction mechanisms for L-LTP at thalamic input synapses to the lateral amygdala: requirement of mGluR5 activation. Neuroreport 13: 685-691.

Lee HK, Takamiya K, Han JS, Man H, Kim CH, Rumbaugh G, Yu S, Ding L, He C, Petralia RS, et al. 2003. Phosphorylation of the AMPA receptor GluR1 subunit is required for synaptic plasticity and retention of spatial memory. Cell 112: 631-643.

Lee HK, Takamiya K, He K, Song L, Huganir RL. 2010. Specific roles of AMPA receptor subunit GluR1 (GluA1) phosphorylation sites in regulating synaptic plasticity in the CA1 region of hippocampus. J Neurophysiol 103: 479-489.

Li HB, Mao RR, Zhang JC, Yang Y, Cao J, Xu L. 2008. Antistress effect of TRPV1 channel on synaptic plasticity and spatial memory. Biol Psychiatry 64: 286-292.

Lucas SJ, Bortolotto ZA, Collingridge GL, Lodge D. 2013. Selective activation of either mGlu2 or mGlu3 receptors can induce LTD in the amygdala. Neuropharmacology 66: 196-201.

Maione S, Cristino L, Migliozzi AL, Georgiou AL, Starowicz K, Salt TE, Di Marco V. 2009. TRPV1 channels control synaptic plasticity in the developing superior colliculus. J Physiol 587: 2521-2535.

Menigoz A, Ahmed T, Sabanov V, Philippaert K, Pinto S, Kerselaers S, Segal A, Freichel M, Voets T, Nilius B, et al. 2016. TRPM4-dependent post-synaptic depolarization is essential for the induction of NMDA receptor-dependent LTP in CA1 hippocampal neurons. Pflugers Arch 468: 593-607.

Müller T, Albrecht D, Gebhardt C. 2009. Both NR2A and NR2B subunits of the NMDA receptor are critical for long-term potentiation and long-term depression in the lateral amygdala of horizontal slices of adult mice. Learn Mem 16: 395-405.

Nedelescu H, Kelso CM, Lázaro-Muñoz G, Purpura M, Cain CK, LeDoux JE, Aoki C. 2010. Endogenous GluR1-containing AMPA receptors translocate to asymmetric synapses in the lateral amygdala during the early phase of fear memory formation: an electron microscopic immunocytochemical study. J Comp Neurol 518: 4723-4739.

Palomero-Gallagher N, Bidmon HJ, Zilles K. 2003. AMPA, kainate, and NMDA receptor densities in the hippocampus of untreated male rats and females in estrus and diestrus. J Comp Neurol 459: 468-474.

Prange-Kiel J, Fester L, Zhou L, Jarry H, Rune GM. 2009. Estrus cyclicity of spinogenesis: underlying mechanisms. J Neural Transm (Vienna) 116: 1417-1425.

Rumpel S, LeDoux J, Zador A, Malinow R. 2005. Postsynaptic receptor trafficking underlying a form of associative learning. Science 308: $83-88$.

Sabaliauskas N, Shen H, Molla J, Gong QH, Kuver A, Aoki C, Smith SS. 2015 Neurosteroid effects at $\alpha 4 \beta \delta \mathrm{GABA}_{\mathrm{A}}$ receptors alter spatial learning and 
synaptic plasticity in CA1 hippocampus across the estrous cycle of the mouse. Brain Res 1621: 170-186.

Sah P, Lopez De Armentia M. 2003. Excitatory synaptic transmission in the lateral and central amygdala. Ann N Y Acad Sci 985: 67-77.

Schubert M, Albrecht D. 2008. Activation of kainate GLU(K5) transmission rescues kindling-induced impairment of LTP in the rat lateral amygdala. Neuropsychopharmacology 33: 2524-2535.

Schubert M, Drephal C, Albrecht D. 2008. Gender-dependent ATPA-induced changes in long-term potentiation in the rat lateral amygdala. FASEB $J$ 22: $1268-1274$.

Selcher JC, Xu W, Hanson JE, Malenka RC, Madison DV. 2012. Glutamate receptor subunit GluA1 is necessary for long-term potentiation and synapse unsilencing, but not long-term depression in mouse hippocampus. Brain Res 1435: 8-14.

Selvakumar B, Huganir RL, Snyder SH. 2009. S-nitrosylation of stargazin regulates surface expression of AMPA-glutamate neurotransmitter receptors. Proc Natl Acad Sci 106: 16440-16445.

Staschewski J, Kulisch C, Albrecht D. 2011. Different isoforms of nitric oxide synthase are involved in angiotensin-(1-7)-mediated plasticity changes in the amygdala in a gender-dependent manner. Neuroendocrinology $\mathbf{9 4 :}$ 191-199.

Tchekalarova J, Albrecht D. 2007. Angiotensin II suppresses long-term depression in the lateral amygdala of mice via L-type calcium channels. Neurosci Lett 415: 68-72.

Tran L, Keele NB. 2016. CaMKIIalpha knockdown decreases anxiety in the open field and low serotonin-induced upregulation of GluA1 in the basolateral amygdala. Behav Brain Res 303: 152-159.
Traynelis SF, Wollmuth LP, McBain CJ, Menniti FS, Vance KM, Ogden KK, Hansen KB, Yuan H, Myers SJ, Dingledine R. 2010. Glutamate receptor ion channels: structure, regulation, and function. Pharmacol Rev 62: 405-496.

Vekovischeva OY, Aitta-Aho T, Echenko O, Kankaanpää A, Seppälä T, Honkanen A, Sprengel R, Korpi ER. 2004. Reduced aggression in AMPA-type glutamate receptor GluR-A subunit-deficient mice. Genes Brain Behav 3: 253-265.

von Bohlen und Halbach O, Albrecht D. 2002. Reciprocal connections of the hippocampal area CA1, the lateral nucleus of the amygdala and cortical areas in a combined horizontal slice preparation. Neurosci Res 44: 91-100.

Warren SG, Humphreys AG, Juraska JM, Greenough WT. 1995. LTP varies across the estrous cycle: enhanced synaptic plasticity in proestrus rats. Brain Res 703: $26-30$.

Zamanillo D, Sprengel R, Hvalby O, Jensen V, Burnashev N, Rozov A, Kaiser KM, Köster HJ, Borchardt T, Worley P, et al. 1999. Importance of AMPA receptors for hippocampal synaptic plasticity but not for spatial learning. Science 284: 1805-1811.

Zschenderlein C, Gebhardt C, von Bohlen und Halbach O, Kulisch C, Albrecht D. 2011. Capsaicin-induced changes in LTP in the lateral amygdala are mediated by TRPV1. PLoS One 6: e16116.

Received May 24, 2017; accepted in revised form September 14, 2017. 


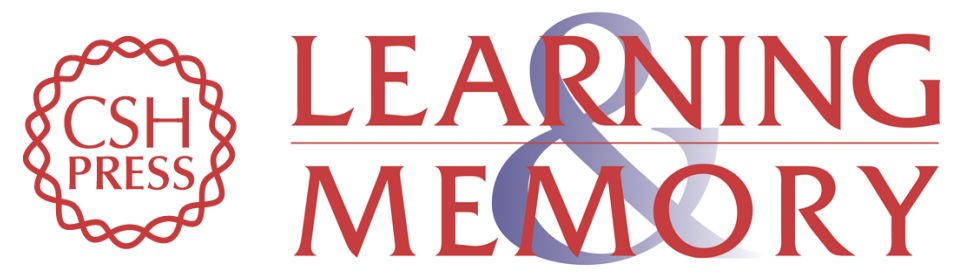

\section{Glutamate receptor GluA1 subunit is implicated in capsaicin induced modulation of amygdala LTP but not LTD}

Christine Gebhardt and Doris Albrecht

Learn. Mem. 2018, 25:

Access the most recent version at doi:10.1101/Im.045948.117

References This article cites 48 articles, 10 of which can be accessed free at: http://learnmem.cshlp.org/content/25/1/1.full.html\#ref-list-1

Creative This article is distributed exclusively by Cold Spring Harbor Laboratory Press for the Commons License first 12 months after the full-issue publication date (see

http://learnmem.cshlp.org/site/misc/terms.xhtml). After 12 months, it is available under a Creative Commons License (Attribution-NonCommercial 4.0 International), as described at http://creativecommons.org/licenses/by-nc/4.0/.

Email Alerting Receive free email alerts when new articles cite this article - sign up in the box at the Service top right corner of the article or click here. 